\title{
An integrin aEß37-dependent mechanism of IgA transcytosis requires direct plasma cell contact with intestinal epithelium
}

\author{
Mauricio Guzman ${ }^{1,2}$, Luke R. Lundborg ${ }^{1,2}$, Shaila Yeasmin ${ }^{1,2}$, Christopher J. Tyler ${ }^{1,2}$, Nadia R. Zgajnar ${ }^{1,2}$, Vanessa Taupin ${ }^{3}$, \\ Katarzyna Dobaczewska ${ }^{4}$, Zbigniew Mikulski ${ }^{4}$, Giorgos Bamias ${ }^{5}$ and Jesús Rivera-Nieves (10 ${ }^{1,2 \llbracket}$
}

This is a U.S. government work and not under copyright protection in the U.S.; foreign copyright protection may apply 2021

Efficient IgA transcytosis is critical for the maintenance of a homeostatic microbiota. In the canonical model, locally-secreted dimeric (d) IgA reaches the polymeric immunoglobulin receptor (plgR) on intestinal epithelium via simple diffusion. A role for integrin aE (CD103) $\beta 7$ during transcytosis has not been described, nor its expression by intestinal $B$ cell lineage cells. We found that aEdeficient $\left(\mathrm{aE}^{-/-}\right)$mice have a luminal IgA deficit, despite normal antibody-secreting cells (ASC) recruitment, local lgA production and increased plgR expression. This deficit was not due to dendritic cell (DC)-derived retinoic acid (RA) nor class-switching defects, as stool from $\mathrm{RAG}^{-/-}$mice reconstituted with $\mathrm{aE}^{-/-} \mathrm{B}$ cells was also IgA deficient. Flow cytometric, ultrastructural and transcriptional profiling showed that aE $\beta 7$-expressing ASC represent an undescribed subset of terminally-differentiated intestinal plasma cells (PC) that establishes direct cell to cell contact with intestinal epithelium. We propose that lgA not only reaches plgR through diffusion, but that $\mathrm{aE} \beta 7+\mathrm{PC}$ dock with E-cadherin-expressing intestinal epithelium to directly relay lgA for transcytosis into the intestinal lumen.

Mucosal Immunology (2021) 14:1347-1357; https://doi.org/10.1038/s41385-021-00439-x

\section{INTRODUCTION}

Secretory Immunoglobulin A (SIgA) is critical for the control of the intestinal microbiota. Therefore, luminal IgA levels are tightly maintained by a sequence of processes that include $B$ cell progenitor production at the bone marrow, naïve $B$ cell migration to inductive sites, (e.g., Peyer Patches (PP)), immunoglobulin (Ig)A class-switching in germinal centers, IgA plasmablast egress and recruitment into intestinal lamina propria (LP), maturation/survival of plasma cells (PC), local IgA production by antibody-secreting cells (ASC), and polymeric Immunoglobulin receptor (plgR)mediated epithelial transcytosis into the intestinal lumen. Both integrin $37-$ and MAdCAM-1-deficient mice exhibit underdeveloped PP and an $\lg A+A S C$ deficit in the LP, underlining the importance of integrin $\alpha 4 \beta 7: M A d C A M-1$ interactions for naïve $B$ cell migration to PP and intestinal recruitment of $\lg A$ plasmablasts. ${ }^{1-3}$ In contrast, the expression and functions of integrin $a E$ (CD103) $\beta 7$ appear to be much narrower.

aE 37 was first described as the HML- 1 antigen generated by immunization of mice with human intestinal intraepithelial lymphocytes (IEL). ${ }^{4}$ Subsequently, the antibodies HML- 1 and B-Ly7 were identified to recognize the same molecule: integrin $\mathrm{aE}^{5}$ expressed abundantly on the cell surface of malignant $\mathrm{B}$ cells. CD103 is widely used as a surface marker for hairy cell leukemia, a $B$ cell cancer. ${ }^{6}$ aE $\beta 7$ is expressed by intraepithelial lymphocytes $(\mathrm{IEL})^{7}$ and mediates their interactions with intestinal epithelial cells (IEC) via E-cadherin. ${ }^{8,9}$ A mucosal dendritic cell (DC) subset also expresses $a E \beta 7 .^{10}$ This DC subset was later found to be a major producer of retinoic acid (RA) ${ }^{11}$, critical for induction of a guthoming phenotype, regulatory $\mathrm{T}$ cells (Treg) and IgA classswitching. ${ }^{12-14}$ However, the physiologic role of the integrin in this DC subset remains unclear, as $C D 103^{-/-}$DC are not impaired on their ability to imprint a gut-homing phenotype to $\mathrm{T}$ cells. ${ }^{15}$ aE $\beta 7$ has also been reported in a subset of $B$ cells at the nasal mucosa and the head and neck. ${ }^{16,17}$ In the intestine, by contrast, neither its expression by cells of the $B$ cell lineage nor its potential involvement in IgA luminal transport have been recognized. ${ }^{18}$ Here, we report on an undescribed subset of terminallydifferentiated aE 37 -expressing $\lg ^{+} \mathrm{PC}$ that establish direct contact with E-cadherin/plgR-expressing IEC. We identify a new role for $a E \beta 7$ during $\lg A$ transcytosis and propose a novel mechanism of direct IgA relay to IEC by PC for its transcytosis into the intestinal lumen.

\section{RESULTS}

Fecal IgA is lower in integrin aE-deficient mice despite normal $B$ cell recruitment, IgA production and increased plgR mRNA expression

$\beta 7$-deficient mice $\left(\beta 7^{-/-}\right)$have dual integrins $\alpha 4 \beta 7$ and $\alpha E \beta 7$ deficits. IgA ASC are decreased in their intestinal lamina propria. This finding is attributable to the absence of a4 $\beta 7 / M A d C A M-1-$ mediated ASC recruitment rather than to the aE $\beta 7$ defect, as this is also observed in MAdCAM-1-deficient mice ${ }^{1,3}$. The maintenance of luminal secretory (S) $\lg A$ levels is dependent on several

\footnotetext{
${ }^{1}$ Gastroenterology Section, San Diego VA Medical Center, La Jolla Village Drive, San Diego, CA, USA. ${ }^{2}$ Division of Gastroenterology, Department of Medicine, University of California San Diego, La Jolla, CA, USA. ${ }^{3}$ Electron Microscopy Core Facility, Department of Cellular and Molecular Medicine, University of California San Diego, La Jolla, CA, USA. ${ }^{4}$ Microscopy and Histology Core, La Jolla Institute of Allergy and Immunology, La Jolla, CA, USA. ${ }^{5}$ GI Unit, 3rd Academic Department of Internal Medicine, National and Kapodistrian University of Athens, Sotiria Hospital, Athens, Greece. ${ }^{凶}$ email: jriveranieves@ucsd.edu
}

Received: 11 March 2021 Revised: 9 July 2021 Accepted: 31 July 2021

Published online: 20 August 2021 

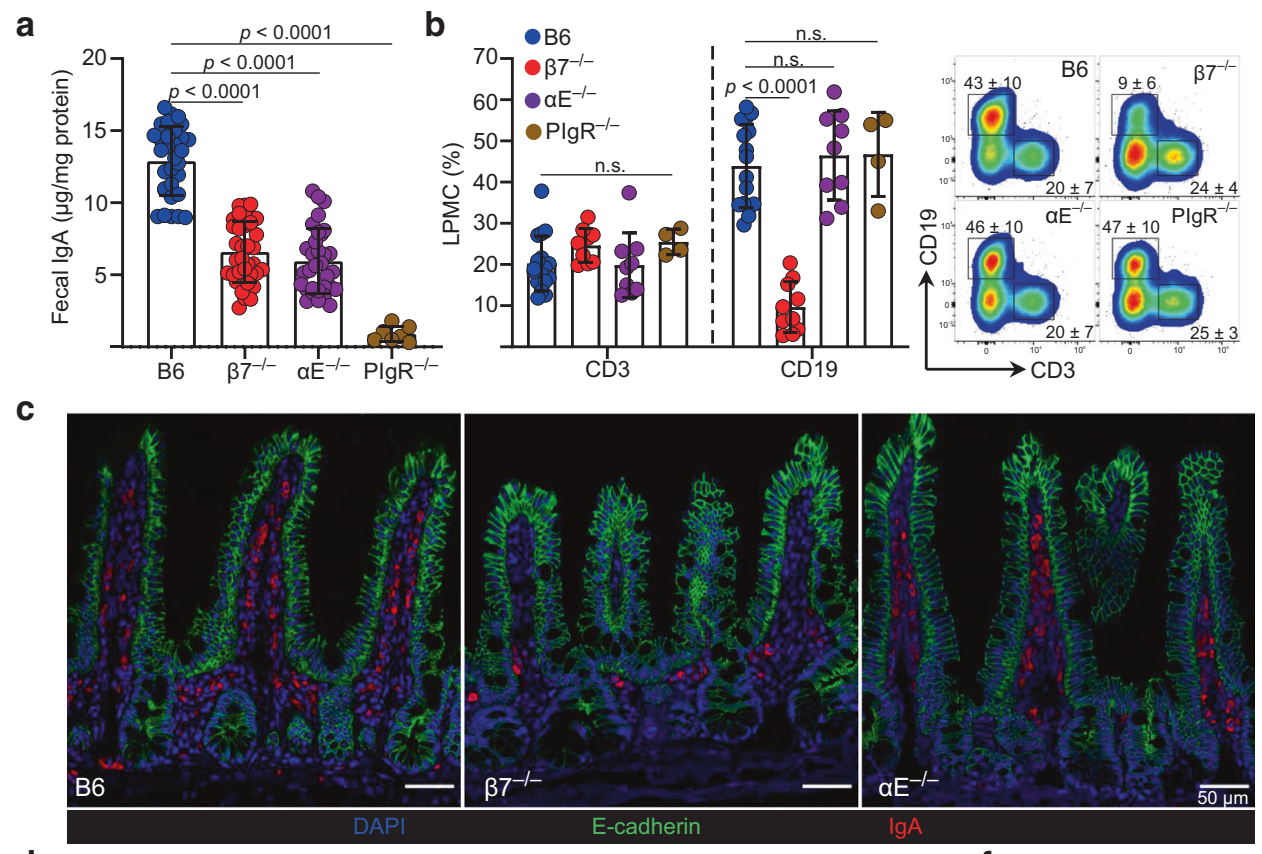

d
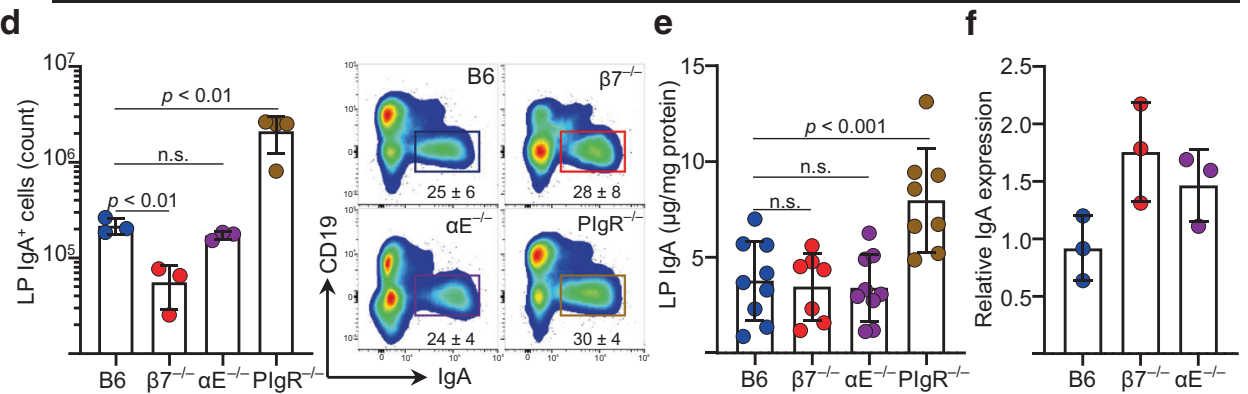

g

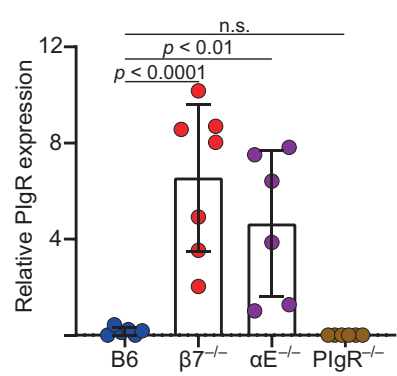

h

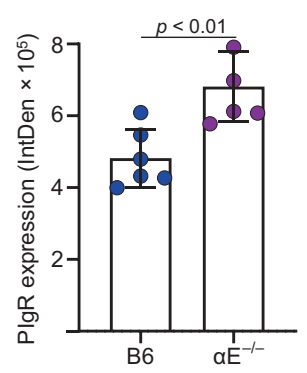

i $\mathrm{B} 6$
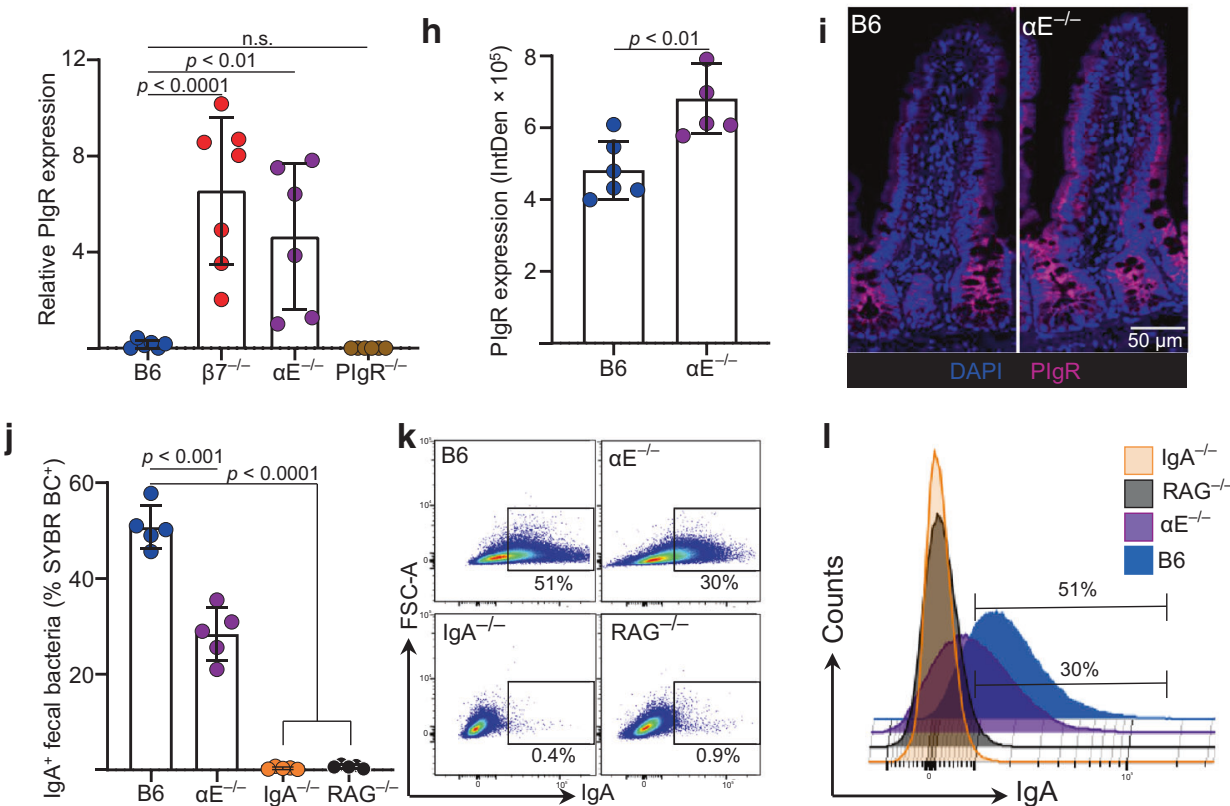

processes that include: 1. IgA plasmablast recruitment, 2. local $\lg A$ production and 3. plgR-mediated transcytosis. We measured fecal $\mathrm{SIgA}$ as a surrogate indicator of the integrity of these processes in C57BL6 (B6), $\beta 7^{-1-}$ and $\mathrm{aE}^{-1-}$ mice, using plgR-deficient mice $\left(\right.$ plgR $^{-1-}$ ) as controls. Unexpectedly, not only $\beta 7^{-1-}$ but also $\mathrm{aE}^{-1-}$ mice had lower fecal IgA than B6 mice (Fig. 1a). To exclude a recruitment deficit, we analyzed the mononuclear cell composition of their ileal LP. CD19 ${ }^{+}$B cells were decreased only in the $\mathrm{LP}$ of $\beta 7^{-/-}$, but not in $a \mathrm{E}^{-/-}$mice. By contrast, the percentage of $\mathrm{CD} 3+\mathrm{T}$ cells was uniformly unaffected (Fig. 1b), suggesting alternate integrin use by $T$ cells for intestinal recruitment. Immunofluorescence (IF) confirmed impaired $\lg \mathrm{A}^{+}$ ASC recruitment only in $\beta 7^{-1-}$ mice but not in $\mathrm{aE}^{-1-}$ mice (Fig. 1c). The $T$ and $B$ cell composition of the spleen and mesenteric lymph 
Fig. 1 Integrin aE deficiency leads to a fecal IgA deficit despite normal $B$ cell recruitment, IgA production and increased plgR mRNA expression. a Fecal IgA levels measured by ELISA in C57BL/6 (WT), Itgb7 ${ }^{-1-}\left(\beta 7^{-/-}\right)$, Itgae ${ }^{-1-}\left(\alpha \mathrm{E}^{-/-}\right)$and plgR-deficient (plgR $\left.{ }^{-1-}\right)$ mice. b Percentage of CD3+ and CD19+ cells within the ileal LP of indicated strains and representative contour plots of indicated cell subsets gated on live, single cellular events. c IF staining of IgA + ASC and E-cadherin, representative coronal images of terminal ileum (TI). d Absolute numbers and representative dot plots of $\lg A+A S C s$ in lamina propria. e LP IgA levels measured by ELISA of indicated strains (f) ileal IgA mRNA transcripts in ilea of indicated mice (g) plgR mRNA expression in ileum of indicated mice. $\mathbf{h}$ Relative plgR fluorescence intensity expressed as integrated density (IntDent, see "Methods") per villi and (i) representative IF images (j) Percentage of IgA-coated fecal bacteria measured by flow cytometry and $(\mathbf{j}, \mathbf{k}, \mathbf{I})$ representative plots and histograms of IgA coating of indicated mouse strains. Each data point (mean \pm SD) represent a single mouse with $n \geq 5$ from 2 or 3 independent experiments. Statistical significance determined using two-way ANOVA with Dunnett's multiple comparisons test.

nodes (MLN) was not different between any strain, in support of an intestinal-specific $B$ cell recruitment deficit in $\beta 7^{-1-}$ mice (Supplementary Fig. 1a, b). Absolute counts of $\lg \mathrm{A}^{+}, \lg \mathrm{D}^{+}$and $\operatorname{lgM}^{+} \mathrm{ASC}$ were also lower only in $\beta 7^{-1-}$ mice, as shown previously for $\lg \mathrm{A}^{+} \mathrm{ASC}^{1}$ (Fig. 1d, Supplementary Fig. 1c, d). Thus, all ASC were reduced in $\mathrm{LP}$ of $\beta 7^{-1-}$ mice, not only $\lg \mathrm{A}^{+} \mathrm{ASC}$.

We then evaluated whether defective local IgA production could account for the luminal $\lg A$ deficit. $\lg A$ levels within the intestinal $L P$ was similar between $B 6, \beta 7^{-1-}$ and $a E^{-1-}$ mice (Fig. 1e), whereas $\mathrm{plgR}^{-1-}$ mice had higher levels, as reported previously. ${ }^{19} \mathrm{CD} 19^{+} \mathrm{B}$ cells from all strains also showed equal ability to IgA class-switch ex vivo (Supplementary Fig. 1e, f). Given the remarkable ability of $\beta 7^{-/-}$mice to maintain luminal SIgA to a level comparable to that of $\mathrm{aE}^{-/-}$mice, despite their marked recruitment deficit, we examined their $\lg A$ mRNA transcripts. These were higher in $\beta 7^{-/-}$mice, suggesting that IgA + ASC may sense and adapt to the luminal $\lg A$ deficit by enhancing their production of IgA (Fig. 1f).

As all intraluminal $\lg A$ is produced locally and transcytosed by plgR, we excluded a plgR deficit as an explanation for the low luminal IgA by quantifying ileal plgR mRNA transcripts. ${ }^{20}$ Transcripts were actually higher in both $\beta 7^{-1-}$ and $a E^{-1-}$ mice, compared with $\mathrm{B} 6$ and $\mathrm{plgR}^{-/-}$mice (Fig. 1g). plgR upregulation is a second mechanism through which these strains maintain luminal IgA levels. We confirmed PlgR protein overexpression by IF (Fig. 1h, i). Increased fluorescent signal was quantified in an unbiased fashion using Fiji ImageJ software. The product of the area and mean intensity (Int Den) were recorded for $\mathrm{B} 6$ and $\mathrm{aE}^{-/-}$mice (Fig. 1h).

Finally, to begin to understand possible in vivo implications of a potential aE-dependent transcytosis defect, we compared fecal bacterial $\lg \mathrm{A}$ coating in $\mathrm{aE}^{-/-}$and $\mathrm{B} 6$ mice, using bacteria from $\lg \mathrm{A}^{-1-}$ and $\mathrm{RAG}^{-1-}$ mice as controls. We observed a significant decrease in bacterial lgA coating in stool of $a E^{-/-}$mice (Fig. $1 \mathrm{j}, \mathrm{k}, \mathrm{i}$ ). Taken together, these findings demonstrate that the fecal $\lg A$ deficit in $\mathrm{aE}^{-1-}$ mice could not be explained by impaired $\mathrm{B}$ cell/lgA ASC recruitment, local IgA production, IgA class switching nor plgR expression. Instead, integrin $a E \beta 7$ appeared to play an unappreciated role for the maintenance of luminal SIgA levels and bacterial $\lg \mathrm{A}$ coating.

\section{Transfer of aE-deficient B cells to RAG $^{-1-}$ mice recapitulated the luminal IgA deficit, excluding an $a E \beta 7^{+}$dendritic cell-derived retinoic acid deficit as a cause}

In 1993 a subset of intestinal DC were found to express integrin aE $\beta 7 .{ }^{10}$ These were later shown to produce $R A^{11}$, an important factor for imprinting a gut-homing (CCR9, a4 37 ) and regulatory T cell (Treg) phenotypes on lymphocytes and for IgA class-switching in ASC. ${ }^{12}$ To examine whether the luminal IgA deficit in $\mathrm{aE}^{-/-}$and $\beta 7^{-1-}$ mice could be related to the absence of $\mathrm{CD}_{103}{ }^{+} \mathrm{DC}$ and impaired RA synthesis, we co-transferred $\mathrm{B} 6 \mathrm{CD} 4^{+} \mathrm{T}$ cells along with $\mathrm{CD} 19^{+} \mathrm{B}$ cells from $\mathrm{B} 6$ (controls), $\beta 7^{-1-}$ or $\mathrm{aE}^{-1-} \mathrm{B}$ cells into $\mathrm{RAG}^{-1-}$ mice, which have an intact DC/RA system ${ }^{21,22}$ (Fig. 2a). As observed in donor mice, fecal SIgA was lower in recipients of $\beta 7^{-1-}$ and $a E^{-1-} B$ cells (Fig. 2b). ELISA, flow cytometry and confocal microscopy analysis showed that $\mathrm{LP} \lg A$ and $\lg A+A S C$ were lower only in mice receiving $\beta 7^{-1-} B$ cells, reflective a $B$ cell recruitment deficit only in the latter strain (Fig. 2c-f)).
As observed with $\beta 7^{-/-}$or $\mathrm{aE}^{-/-}$mice, plgR expression was higher in ilea of mice transferred with either $\beta 7^{-/-}$or $a E^{-1-} B$ cells (both with luminal lgA deficits) (Fig. 2g), but not in those receiving B6 B cells. The percentage of $B$ and T cells in the spleen and MLN of RAG ${ }^{-1}$ mice reconstituted with either $\beta 7^{-/-}$or $\mathrm{aE}^{-/-}$donor cells was normal, as were the percentages of CD4+ T cells in both the LP and periphery (Supplementary Fig. 2a-c), confirming effective $T$ and $B$ cell reconstitution. Thus, our results show that $\beta 7^{-1-} B$ cells, but not $\mathrm{aE}^{-1-} \mathrm{B}$ cells were impaired in their ability to migrate, populate the $\mathrm{LP}$ or IgA class-switch. Yet, the luminal SIgA deficit persisted. Furthermore, by utilizing an experimental system in which only $B$ cells lack the integrin, we exclude a shortfall of RA-producing $C D 103^{+} \mathrm{DC}$ as the cause for the lower fecal SIgA in $\beta 7^{-1-}$ and $\mathrm{aE}^{-/-}$mice.

\section{A subset of IgA + ASC expressed $\alpha E \beta 7$ and had ultrastructural and transcriptional profiles consistent with that of terminally- differentiated plasma cells}

Surface $\alpha E \beta 7$ protein expression on a subset of CD19 ${ }^{\text {neg }} \lg A+A S C$ was confirmed by flow cytometry in C57BL6 mice, which additionally allowed sorting of ileal LP B cell lineage cells, based on CD19, surface IgA expression and co-expression of integrin subunits $\mathrm{aE}$ and $\beta 7$. We identified 4 main subsets: subset(s) 1 $\left[C D 19^{+} \lg A^{\text {neg }}\right.$ ], s2 [class switched $C D 19^{+} \lg A^{+}$plasmablasts], s3 $\left[C D 19^{\text {neg }} \operatorname{lgA}^{+} a E \beta 7^{\text {neg }} P C\right]$, and s4 [CD19 $\left.{ }^{\text {neg }} \operatorname{lgA} A^{+} a E \beta 7^{\text {pos }} P C\right]$ (Fig. 3a). S1 was mostly $\operatorname{lgD}+$ and a third also $\lg M$ positive, suggesting that they were in earlier stages of differentiation (Fig. 3b) and likely originating from inducible lymphoid follicles (ILF). Ultrastructurally, transmission electron microscopy (TEM) showed that their nucleocytoplasmic ratio decreased progressively from $\mathrm{s} 1$ through $\mathrm{s} 4\left(\mathrm{aE} \beta 7^{+}\right)$. The latter had abundant rough endoplasmic reticulum (RER) and low nucleo:cytoplasmic ratio, consistent with terminal differentiation (Fig. 3c, d).

mRNA was extracted from cell subsets sorted as in Fig. 3a and their transcriptomic profiles analyzed by RNA-seq (Fig. 3e). The expression of $B$ cell-related genes representative of distinct stages of B cell maturation ${ }^{23}$ is shown. Overall, gene expression changed the most upon $\lg A$ class switching $\left(\operatorname{CD}_{1} 9^{+}(\mathrm{s} 1,2)\right.$ vs. $\left.\mathrm{CD} 19^{\text {neg }} \lg \mathrm{A}+(\mathrm{s} 3,4)\right)$. $\lg A$ class-switched $(\mathrm{s} 3,4)$ lacked $\mathrm{CD} 19$, known to be shed upon class switching. Similarly, they lacked other surface proteins that are lost with maturation, such as CD38 (lost in mouse PC, not human) and CD20. The CD79a and CD79b proteins form a dimer associated with membrane-bound immunoglobulin, constituting the $B$ cell receptor (BCR), which disappears in the later stages of PC differentiation. Along those lines the costimulatory molecule CD40 on B cells interacts with the CD40L during antigen presentation. The absence of CD40 supports that these cells no longer present antigen, as expected for professional PC. Consistent with a PC identity they expressed syndecan-1 (CD138), a classic marker of mature ASC that binds to extracellular matrix components, integrins, prosurvival cytokines and chemokines. The B220 gene (Ptprc) which like CD19 is often shed by most mature PC was present at the mRNA but not at the protein level by flow cytometry (not shown). Interestingly both $\lg \mathrm{A}^{+}$subsets possess transcripts for lgGFC binding protein (FCGBP), a characteristic secretory product of most mucin-producing cells including Goblet cells. The molecular 


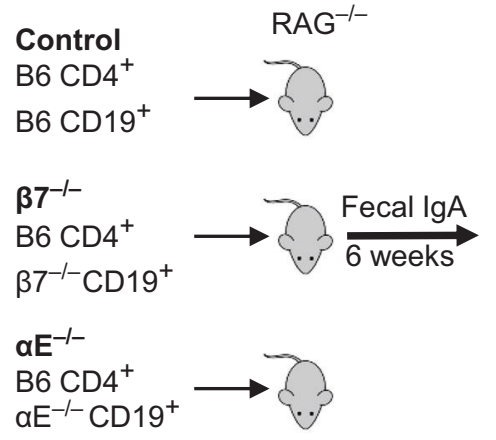

b

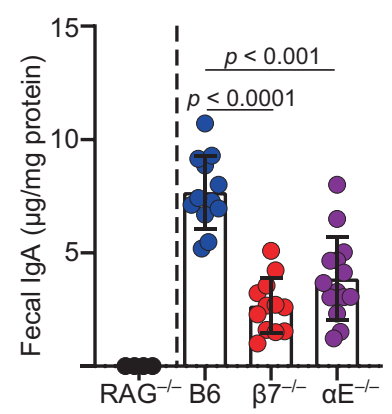

C

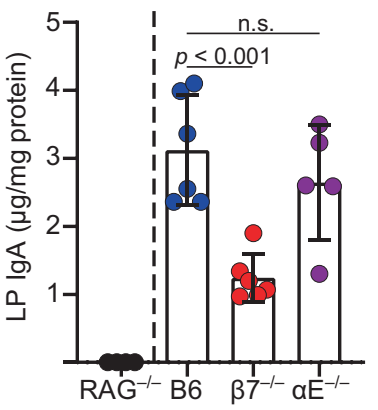

d
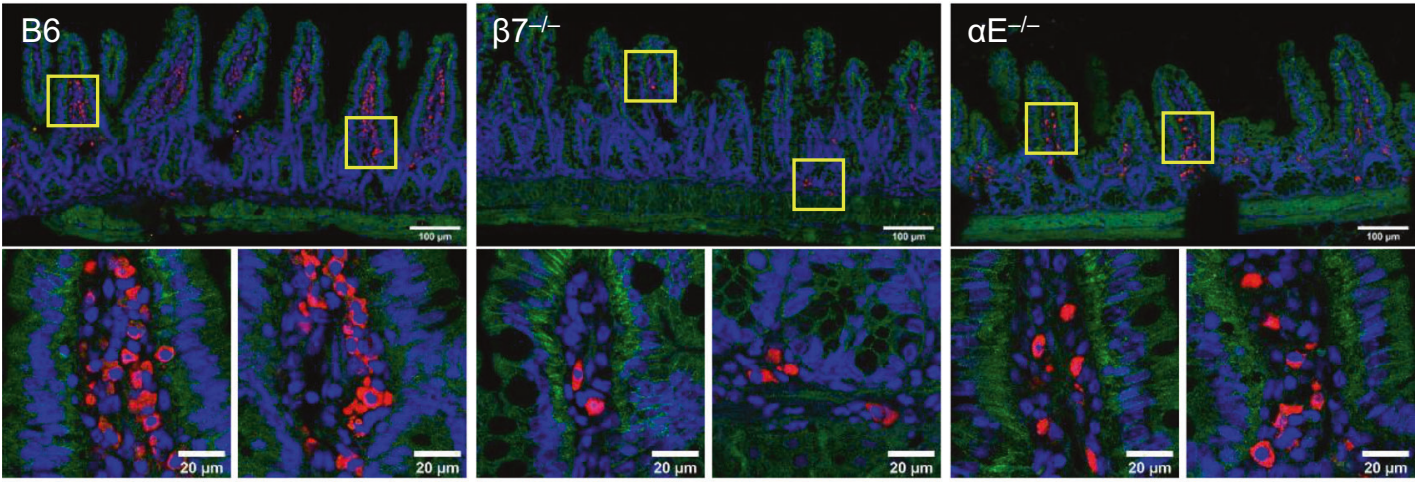

e

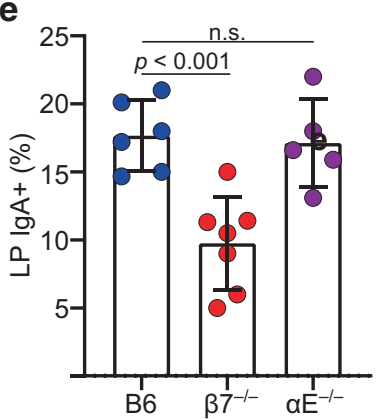

f

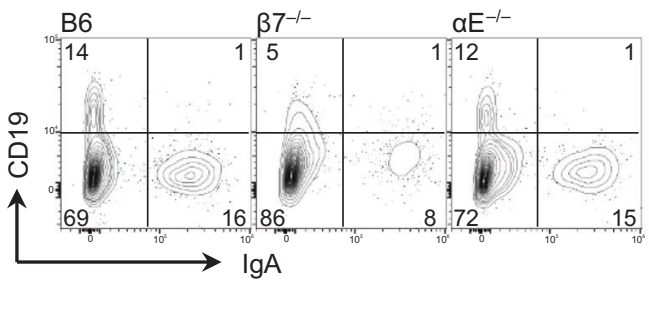

$\mathbf{g}$

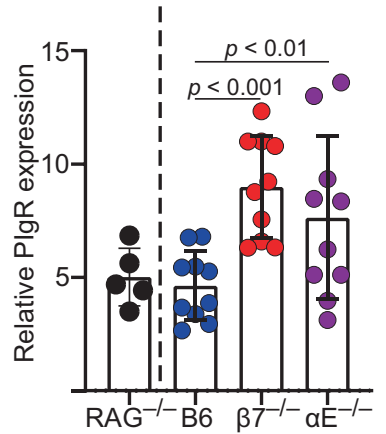

Fig. 2 aE-deficient $B$ cells are unable to reconstitute luminal IgA despite normal recruitment, local Ig production and increased PlgR expression. a Experimental design of adoptive transfers. b Fecal IgA levels measured by ELISA. c LP IgA levels of indicated strains measured by ELISA. d IF staining of IgA + ASC and E-cadherin (representative coronal TI images) of indicated strains. e Percentage of IgA+ cells within the ilea of indicated mouse strains and (f) representative contours plots. $\mathbf{g}$ lleal plgR mRNA expression of RAG ${ }^{-1-}$ mice transferred with B cells of indicated strains (mean $\pm S D, n=6$ to 12 mice from 3 independent experiments, significance determined using ANOVA, followed by Tukey's multiple comparison test.

function of FCGBP has not been elucidated in detail, but it is likely to regulate pathogen attachment and the clearing of microorganisms. Predictably, both s3 and 4 no longer possess transcripts for activation-induced cytidine deaminase (AID, Aicda), an enzyme that mediates somatic hypermutation and class-switch recombination. AID is strongly expressed in s2 (CD19+ $\lg A+)$ which are actively class-switching.

$a E \beta 7^{+} P C(s 4)$ additionally possess transcripts for integrin $\beta 4$ which would allow these cells to bind to laminin. They also expressed gut homing chemokine receptors: CCR9 and CCR10, suggesting they are intestinal-specific. These receptors are involved in epithelial interactions and both of their ligands (CCL25, CCL28) are produced by ileal and colonic epithelial cells. Conversely, they lack S1PR1 and CCR7 (expressed by immature B cells), suggesting that they are tissue residents and do not travel to blood or lymphoid tissues, where their respective ligands S1P1 and CCL19/21 are abundant.
Certain transcription factors expressed by $a E \beta 7^{+} P C$ include Regulator of plasma cell differentiation Prdm1 (Blimp1) ${ }^{24,25}$ and Irf4, essential for the generation of PC. Their function in mature PC remains poorly understood. X-box binding protein 1 (Xbp1), also expressed by $\lg \mathrm{A}+\mathrm{ASC}$ regulates PC differentiation, whereas Zbtb20 promotes PC differentiation and longevity. ${ }^{26}$ Subsets 1 and 2 expressed Pax5 and Bcl6; genes expressed by germinal center $B$ cells ${ }^{27}$, suggesting that they may originate from inducible lymphoid follicles within the intestine. ${ }^{28}$

Several molecules that promote long-term survival are also expressed by both $\lg \mathrm{A}^{+}$ASC $(\mathrm{s} 3,4)$. These include CD28 (receptor for $\mathrm{CD} 80 / 86$ ) and myeloid leukemia cell differentiation protein (MCL-1), both enhance survival through the inhibition of apopotosis. Tnfrsf17, which encodes for B cell maturation antigen (BCMA is expressed by terminally-differentiated long-lived $\mathrm{PC}^{29}$ and recognizes B-cell activating factor (BAFF), which also 

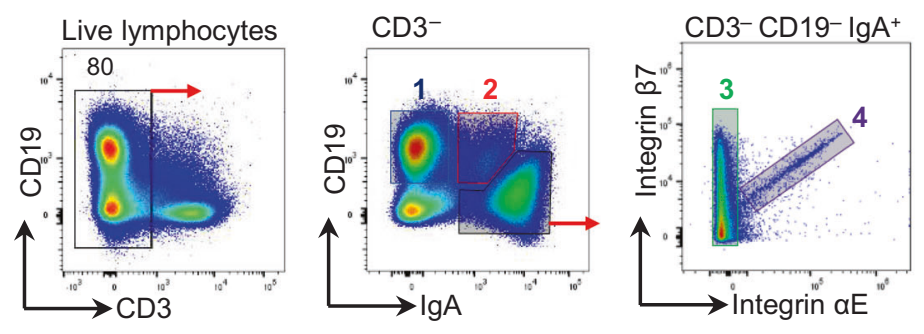

\section{$1 \mathrm{CD}^{+}{ }^{+} \lg \mathrm{A}^{-} \quad 2 \mathrm{CD}^{-} 9^{+} \lg \mathrm{A}^{+}$ \\ $3 \mathrm{CD} 19^{-} \lg \mathrm{A}^{+} \alpha \mathrm{E} \beta 7^{-} \quad 4 \mathrm{CD}^{-} 9^{-} \lg \mathrm{A}^{+} \alpha \mathrm{E} \beta 7^{+}$}

b
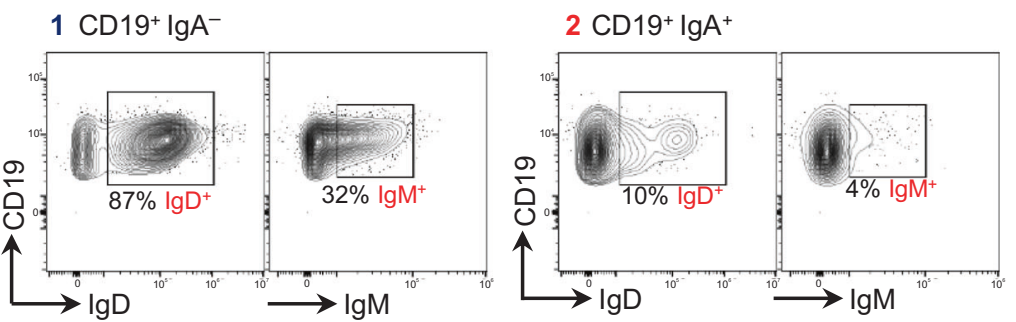

c
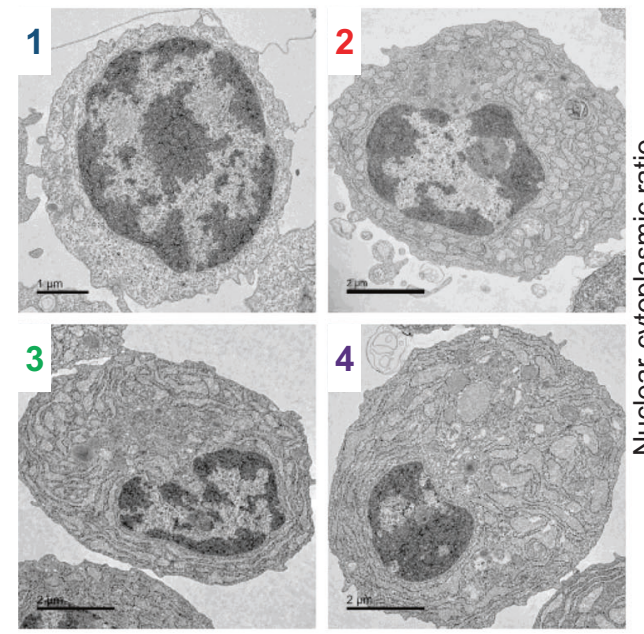

d

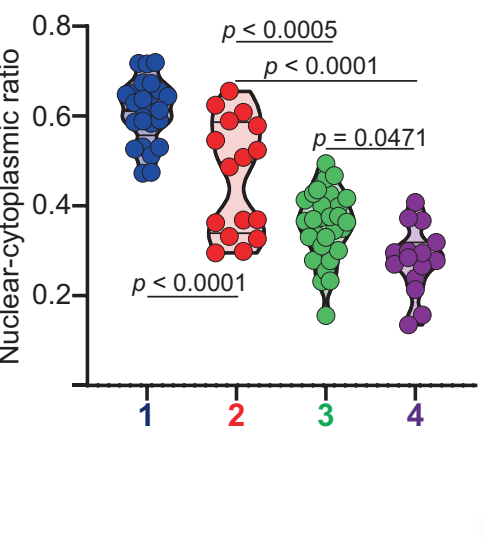

e

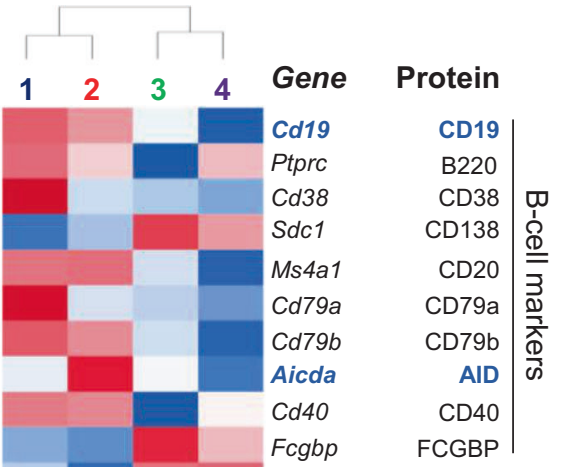

Integrin $\beta 7$

Integrin $\beta 4$

Integrin $\alpha \mathrm{E}$

Integrin $\beta 1$

Integrin $\beta 2$

Integrin $\mathrm{aL}$

CCR7

CCR9

CXCR4

CCR10

S1PR1

PAX5

BCL6

EBF1

$\mathrm{BACH} 2$

Irf-8

SPI-1

SPIB

Blimp-1

Irf4

XBP1

TACI

BAFF-R

BCMA

Ki-67

CD28

MCL-1

ZBTB20

GLUT-1

ZBTB32

EZH2

Fig. $3 a E \beta 7$ + B cells are a subset of terminally-differentiated PC in small intestinal lamina propria. a Sorting strategy for intestinal LP B cell lineage cells. b Representative contours plots of IgD and IgM expression in subsets 1 and 2. c Distinct ultrastructure of subsets (representative images). d Nucleo-cytoplasmic ratio of subsets (violin plot of median and quartiles, $n>5$, from 3 independent experiments, $p$ calculated by one-way ANOVA with Sidak's correction). e Heat map of indicated PC-related genes by RNA-seq (2-way ANOVA, up- or down-regulated >2-fold from 3 independent cell sorts).

promotes survival. The absence of ki67 (MKi67) demonstrate that they are no longer replicating.

\section{IgA ASC align with, contact and/or interdigitate within E- cadherin/plgR-expressing ileal epithelium}

Integrin aE $\beta 7$ mediates IEL interactions with IEC 8,30 via E-cadherin, an adhesion molecule expressed on the epithelial basolateral surface. ${ }^{31}$ Recent intravital microscopy studies have shown that IEL are not anchored, but in constant movement, interacting with multiple IEC. ${ }^{32}$ Cells of the $B$ cell lineage are not considered to express aE $\beta 7$, although some scarce exceptions have been reported. ${ }^{4,33}$ However, we identify a population of $\operatorname{lgA}^{+}$ ASC that align themselves in direct contact with plgR- and E- cadherin-expressing IEC (Fig. 4a, b). Such IgA ASC rarely localized near the villus tips, where expression of plgR is low or absent (Fig. 4a), but rather near the crypt base, where they are frequently found in direct contact with IEC (Fig. 4c). In addition, we find certain $\operatorname{IgA}+$ ASC that like IEL, intercalate between IEC (Fig. 4d, Supplementary $3 a-c$ ) These intraepithelial IgA ASC are absent in $\mathrm{aE}^{-1-}$ mice, suggesting that the integrin is required for such intraepithelial positioning (Supplementary Fig. 3c).

Furthermore, in transversal cuts near the crypt base (crypt crosssection) of B6 mice we find IgA ASC that flatten against IEC and acquire a sickled appearance, as to increase their contact surface with IEC (Fig. 5a). The crypt base is identified by the small luminal diameter (Fig. $5 d, L=$ lumen). Although the sickled appearance is 
a

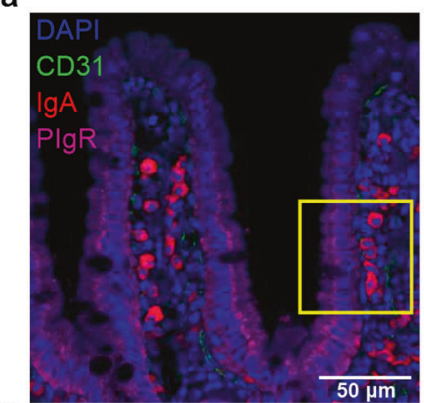

C

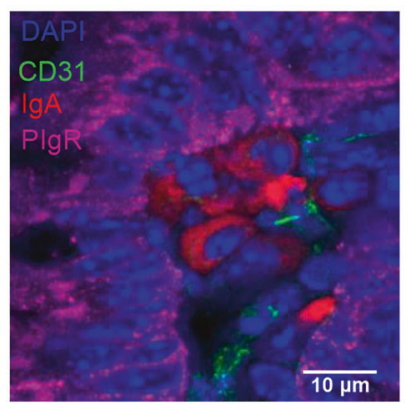

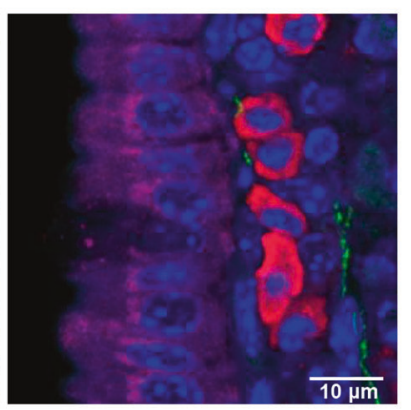

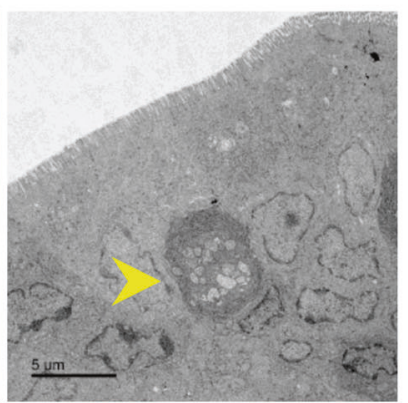

b

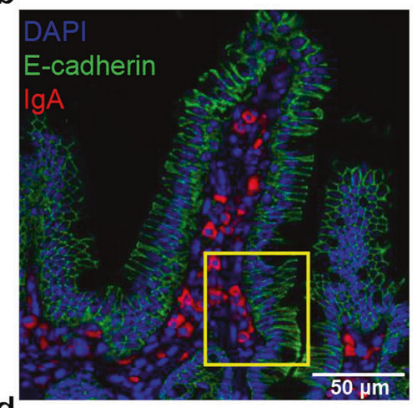

d

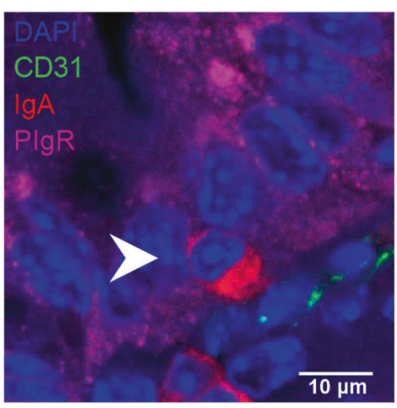

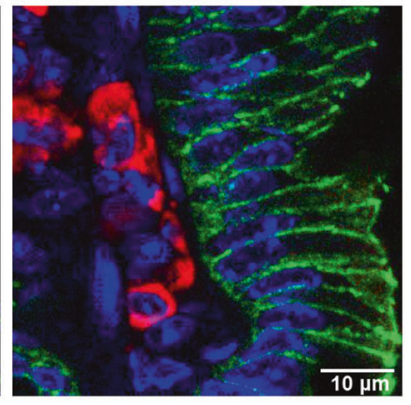

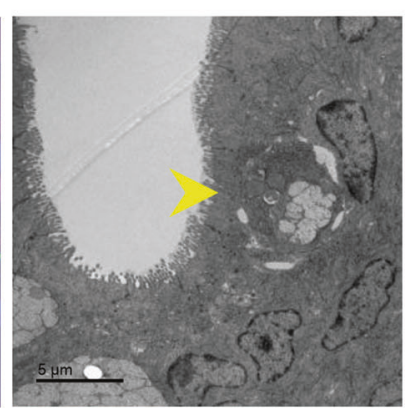

Fig. 4 IgA ASCs align, contact and/or interdigitate E-cadherin/plgR-expressing ileal epithelium. a IF staining of IgA + ASC adjacent to plgRexpressing epithelium (representative images). b IgA + ASC adjacent to E-cadherin-expressing epithelium. $\mathbf{c}, \mathbf{d}$ IF and TEM of IgA + ASC in contact and intercalated within plgR-expressing terminal ileal epithelium (representative images).

obvious when present (Fig. 5a, crypt cross-section, Supplementary Fig. $4 a, b)$ we defined these cells as $>12 \mu \mathrm{m}$ in length, to count them in an unbiased fashion (Supplementary Fig. 4b). Following these criteria, we did not find any elongated IgA + ASC in neither $\beta 7^{-1-}$ nor $a E^{-1-}$ mice (Fig. 5b, c and Supplementary $\left.4 a, b, c\right)$. By contrast round non-adherent $\lg A+$ ASC $(<12 \mu \mathrm{m}$ length), were present in all strains. This supports the hypothesis that the ability of $\lg A+A S C$ to modify their morphology and flatten themselves in contact with IEC is dependent on aE 37 .

TEM, confirmed that cells with sickled morphology and extensive RER containing anti-lgA immunogold-bound particles abut basal crypt IEC (Fig. $5 \mathrm{~d}-\mathrm{f}$ ). IgA and $\mathrm{aE}^{+}$co-expression by dual immunogold particles confirmed that these were IgA + ASC in direct contact with IEC, co-expressing both aE and IgA (Supplementary Fig. 5). Thus, we demonstrate through three independent methods (TEM immunogold, flow cytometry and RNA-seq) that a subset of $\operatorname{lgA}^{+}$ASC express integrin $a E \beta 7$ and establish direct contact with plgR/E-cadherin-expressing IEC near the base of the ileal villus crypt.

\section{DISCUSSION}

The a4 37 integrin has emerged as a major therapeutic target for the inflammatory bowel diseases (IBD) and two drugs that target this integrin (i.e., natalizumab, vedolizumab) are used for the treatment of Crohn's disease and ulcerative colitis. ${ }^{34-36}$ The specificities of these drugs are distinct, as natalizumab targets the shared a4 subunit on $\alpha 4 \beta 7$ and $\alpha 4 \beta 1$, while vedolizumab is specific for $a 4 \beta 7 .{ }^{37}$ Unexpectedly, phase III trials of a third drug (i.e. etrolizumab), that targets the shared $\beta 7$ subunit on both $a 4 \beta 7$ and $a E \beta 7$ did not show similar efficacy in patients with UC (https:// www.roche.com/media/releases/med-cor-2020-08-10.htm.).

Although the failure of a trial drug is multifactorial and cannot be easily attributed to any particular reason, it may illustrate the importance of understanding the potential cellular targets and biological implications of pathway blockade during physiology and pathology.

aE $\beta 7$ is expressed predominantly by $T$ cells, a subset of dendritic cells within mucosal surfaces and by some upper respiratory tract $B$ cells. ${ }^{16}$ However, despite $\mathrm{aE} / \mathrm{CD} 103$ serving as a major diagnostic surface marker of malignant hairy cell leukemia $B$ cells, ${ }^{33}$ the expression of $a E \beta 7$ by gut $B$ cell lineage cells has not been reported to date. ${ }^{18}$ Herein, we describe an unreported population of $\lg \mathrm{A}^{+} \mathrm{ASC}$ that like IEL contact or intercalate within intestinal epithelial cells (IEC). Their elongated sickled morphology, particularly near the crypt base maximizes the surface area in direct contact with the basolateral side of the IEC. Direct relay of $\operatorname{IgA}$ to IEC for transcytosis near the crypt base could contribute to the protection of the stem cell niche from bacterial invasion. The ultrastructure of these ASC is consistent with that of a mature PC, as they have extensive rough endoplasmic reticulum (RER) containing IgA-bound immunogold particles. The potential relevance of the integrin for $\lg A$ transcytosis is highlighted by the fact that the luminal IgA deficit in aE-deficient mice is similar to that of $\beta 7$-deficient mice and by the reduction in bacterial $\lg A$ coating. $\beta 7$-deficient mice additionally have a marked $B$ cell recruitment defect, likely due to their critical dependence on a4ß7:MAdCAM-1 interactions for intestinal homing. Remarkably, they maintain luminal $\operatorname{lgA}$ levels comparable to $\mathrm{aE}^{-1-}$ mice. As part of potential compensatory mechanisms at play, we find higher $\lg \mathrm{A}$ transcripts and increased plgR expression in their terminal ilea. It is likely that other long-term adaptations such as differential PC maturation, fitness and/or longevity are participant as well.

Other explanations for a luminal IgA deficit, such as impaired IgA plasmablast recruitment, plgR downregulation and a CD103 ${ }^{+}$ DC/RA deficit, interfering with regulatory mechanisms or class switching were excluded by the recapitulation of the luminal IgA deficit in $\mathrm{RAG}^{-1-}$ mice transferred with $\mathrm{CD}_{103^{-/-}}$B cells. RAGs have intact RA production and a normal DC compartment. ${ }^{21,22}$ PIgR transcripts were clearly increased, suggesting that the epithelium senses the intraluminal IgA deficit, likely though TLR engagement of pathogen-associated molecular patterns, originating from an altered microbiota composition. ${ }^{38}$ In the ileal LP, we found 3 main B cell subsets, based on their expression of CD19 (shed upon class switching) and surface IgA. The CD19 ${ }^{+}$cells appeared to be in their earliest state of maturation as they had the highest nucleocytoplasmic ratio, expressed IgM, IgD, CCR7, and 
a

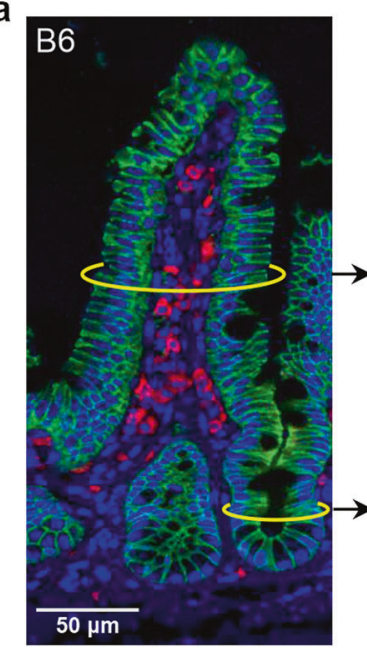

b

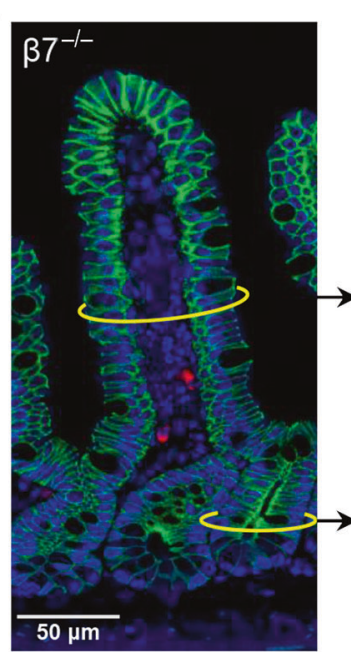

c
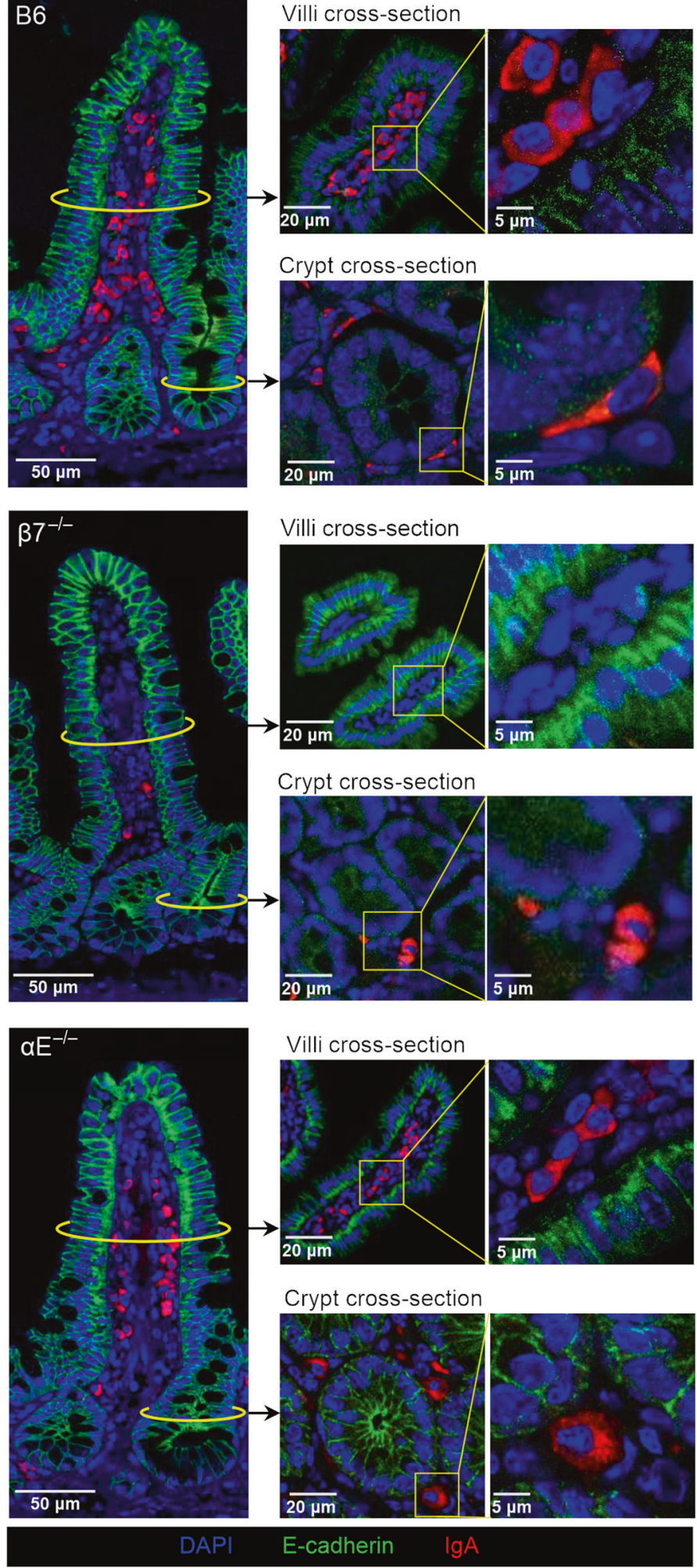

Crypt cross-section

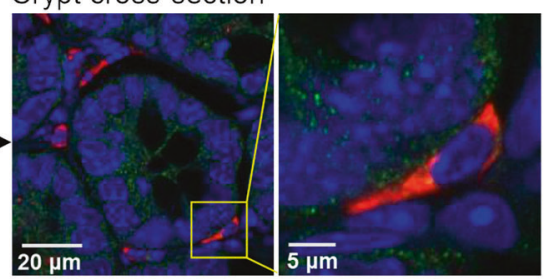

Villi cross-section

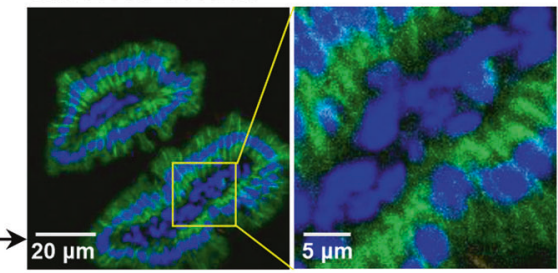

Crypt cross-section

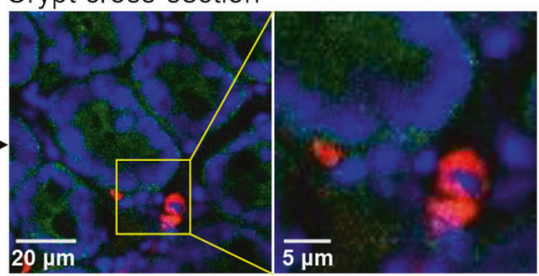

Villi cross-section d

.

f
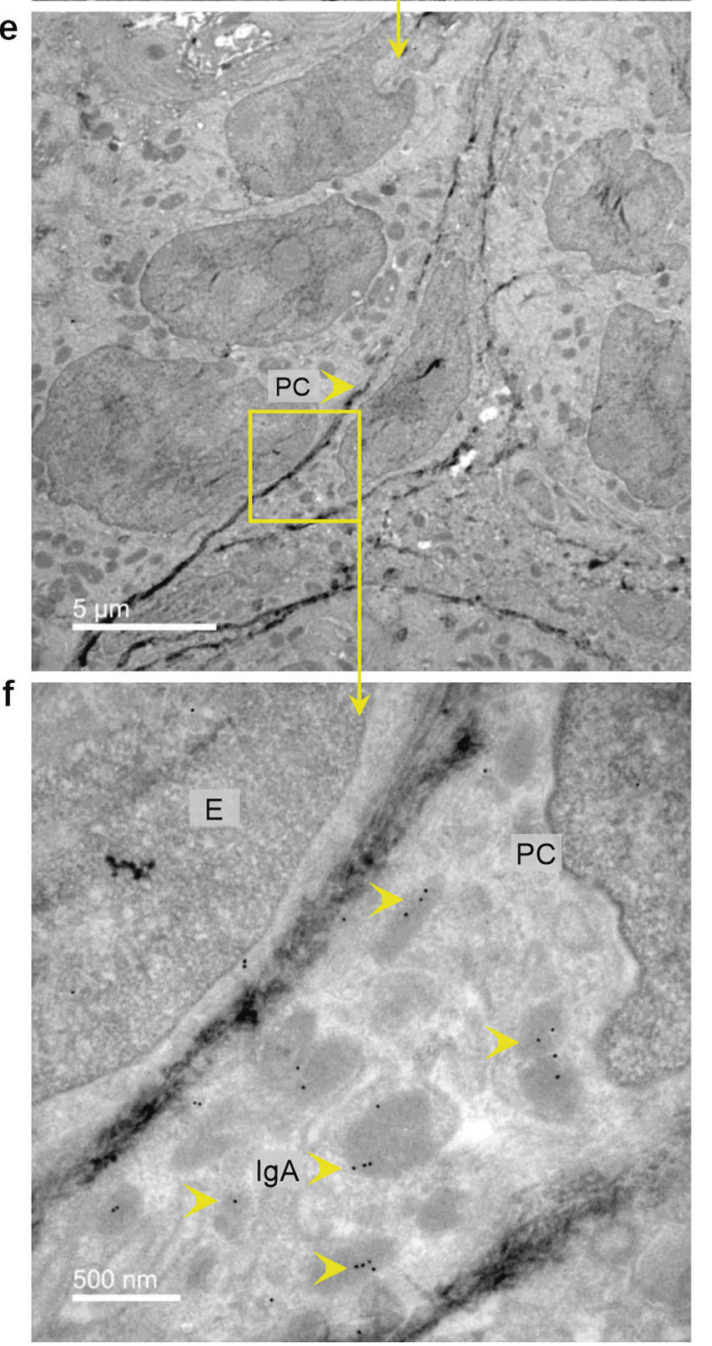

Fig. 5 A subset of $\operatorname{IgA}+$ ASC acquire and elongated/sickled morphology near the crypt base of B6 mice but not in aE- or $\beta 7$-deficient mice. a Round morphology of IgA + ASC in the mid-villous region, whereas a subset of IgA + ASC near the crypt base of B6 mice have an elongated (sickle-like) morphology (coronal and cross sections at indicated levels). b Absence of lgA + ASC in the mid-villous and near crypt base regions in $\beta 7^{-1-}$ mice. c Round morphology of IgA + ASC in the mid-villous region and around the crypt base of $\alpha \mathrm{E}^{-1-}$ mice. Increasing magnification of the villous crypt base of B6 mice (d) Three cells (PC) with sickled morphology in contact with IEC (yellow arrowheads) (e) Higher magnification of an adherent cell with sickled morphology (f) Direct cell to cell contact between IEC and sickled cell with extensive RER and IgA immunogold particles (representative TEM images, $\mathrm{L}=$ lumen, $\mathrm{E}=$ epithelial cell). 
S1PR1. It is possible that these originate from ILF, as these cannot be removed as PP, prior to LPMC extraction. Those $C D 19^{+}$that were class switched expressed AID and KI67, suggesting that they were still replicating. IgA + ASC which had shed C19 (CD19 ${ }^{\text {ne- }}$ $\mathrm{glgA}^{+}$) (subsets 3 and 4) expressed transcripts consistent with terminal differentiation, ${ }^{39}$ such as Blimp-1, syndecan-1 (CD138), Xbp1 and BCMA, while subset 4 also expressed aE 37 .

Thus, we propose that as a late step in PC maturation, a subset of terminally-differentiated $P C$ express $a E \beta 7$ to directly engage $E-$ cadherin/plgR-expressing epithelium in a manner reminiscent of IEL. Direct engagement of PC with IEC may represent an efficient mechanism for direct IgA relay, distinct from the canonical, yet still current model proposed by Brandtzaeg, in which ASC release IgA into the extracellular milieu to eventually reach plgR through diffusion. ${ }^{40}$ The contribution of dlgA by $a E \beta 7^{+} \mathrm{PC}$ to total luminal SIgA is difficult to quantify, as this subset may still be present in the $\mathrm{LP}$ of $\mathrm{aE}^{-/-}$mice contributing to the total $\lg \mathrm{A}$ that will passively reach PlgR for transcytosis. Of note, is that even in $\mathrm{aE}^{-1-}$ mice IgA ASC often line themselves along IEC within the villi, suggesting that they sense IEC-derived chemoatractants (e.g., CCL25) to approximate IEC. It would appear that proximity to IEC may optimize $\lg A$ transfer. The dynamics of the process is unknown, however we observe IgA ASC that appear to be at different stages of IEC engagement, suggesting that this might be a sequential process. Whether IEC engagement is final or these cells may disengage from one area and move to another remains to be ascertained. Given their surface receptor profile, it is likely that these cells are tissue residents and do not circulate.

We report on a subset of intestinal $\lg A+P C$ that express $a E \beta 7$, we demonstrate an unappreciated physiologic role of the integrin for the maintenance of luminal SIgA and propose an alternate mechanism for IgA transcytosis. In this aE $\beta 7$-dependent model, PC dock with intestinal IEC and directly transfer their IgA cargo to plgR, for transfer to the intestinal lumen (Fig. 6). Whether interference with this unappreciated role for the integrin may be in part responsible for the lower efficacy of etrolizumab compared with the a4ß7-specific agent (i.e., vedolizumab) in ulcerative colitis deserves further consideration.

\section{MATERIALS AND METHODS \\ Mice}

C57BL/6 (B6), C57BL/6-Itgb7tm1Cgn (Integrin $\beta 7^{-1-}$ ), B6.129S2(C)Itgaetm1Cmp (Integrin $\mathrm{aE}^{-1-}$ ), B6.129S7-Rag1tm1Mom/J (Rag ${ }^{-1-}$ ) mice were purchased from Jackson Laboratories (Bar Harbor, ME). PlgR $^{-1-}$ mice were provided by Dr. Charlotte Kaetzel (University of Kentucky). $\lg \mathrm{A}^{-/-}$ mice were provided by Dr. Lars Eckmann (San Diego Digestive Diseases Research Center). All mice were maintained under specific pathogen-free conditions and fed with a standard diet and water ad libitum during in vivo studies. Animal procedures were in accordance with governmental and institutional guidelines and approved by the Institutional Animal Care and Use Committees of the University of California San Diego and the San Diego VA Medical Center.

\section{Adoptive transfer studies}

$\mathrm{CD}^{+} \mathrm{T}$ from the spleen and MLN of $\mathrm{B} 6$ mice and $\mathrm{CD} 19^{+} \mathrm{B}$ cells from $\mathrm{B} 6$, $\beta 7^{-1-}$ or $\mathrm{aE}^{-1-}$ mice were enriched by positive selection with anti-mouse CD4 microbeads (130-117-043, Miltenyi Biotec, Auburn, CA) or with antimouse CD19 microbeads (130-121-301, Miltenyi Biotec) respectively, as per the manufacturer's instructions. B6 CD4 ${ }^{+} \mathrm{T}$ cells $\left(\geq 95 \%\right.$ purity; $\left.2.5 \times 10^{6}\right)$ were combined with $\mathrm{CD} 19^{+} \mathrm{B}$ cells from $\mathrm{B} 6, \beta 7^{-/-}$or $\mathrm{aE}^{-/-}$mice $(\geq 95 \%$ purity; $2.5 \times 10^{6}$ ), suspended in $200 \mu \mathrm{L}$ of PBS and injected intraperitoneally into 6 -week-old $\mathrm{RAG}^{-1-}$ recipients. Tissues were harvested after 6 weeks once fecal IgA had reached B6 levels.

\section{Lymphocyte isolation}

Splenocytes, mesenteric lymph node (MLN) lymphocytes were excised and rendered into a cell suspension by mechanical dissociation and sieving through wire mesh as previously described. ${ }^{41}$ Lamina propria (LP) mononuclear cells were isolated from terminal ileum. ${ }^{42}$ Briefly, tissues were flushed out fecal material with cold phosphate-buffered saline (PBS) (14190-144, Gibco, Carlsbad, CA), Peyer's patches were removed, and collected in $30 \mathrm{ml}$ of RPMI-1640 medium (21870-076, Gibco) supplemented with $10 \%$ heat-inactivated fetal calf serum (10082-147, Gibco), $10 \mathrm{mM}$ glutamine, $100 \mathrm{U} / \mathrm{ml}$ penicillin, $100 \mathrm{\mu g} / \mathrm{ml}$ streptomycin $(10378016$, Thermo Fisher Scientific, Waltham, MA). First, samples were washed three times with 1 mM EDTA (GR123, Hoefer, Holliston, MA) in HBSS (14170-112, Gibco) for $15 \mathrm{~min}$ at room temperature in a shaking incubator and once with HBSS without EDTA. Then, intestinal tissue was mechanical dissociated and enzymatically digested in $20 \mathrm{ml}$ of RPMI- 1640 medium containing $10 \% \mathrm{FBS}$, $1.5 \mathrm{mg} / \mathrm{ml}$ Collagenase A (C2139, Sigma-Aldrich, St. Louis, MO) and $0.5 \mathrm{mg} /$ $\mathrm{ml}$ Dispase II (D4693, Sigma-Aldrich) for $30 \mathrm{~min}$ at $37^{\circ} \mathrm{C}$ and $200 \mathrm{rpm}$ in a shaking incubator. Following digestion, tissues were strained to yield a single-cell suspension, centrifuged $10 \mathrm{~min}$ at $1500 \mathrm{rpm}$ at $4{ }^{\circ} \mathrm{C}$. For in vitro stimulation assays, $2.5 \times 10^{5}$ splenocytes were cultured in 96 -well U-bottom plates with or without $50 \mu \mathrm{g} / \mathrm{ml}$ of LPS (00-4976-93, Invitrogen, Carlsbad, CA) for $72 \mathrm{~h}$ and stained for flow cytometry.

\section{Enzyme-linked immunosorbent assay (ELISA)}

Fecal pellets were collected in $1 \mathrm{~mL}$ of phosphate buffer saline (14190-144, Gibco) and vortexed for $10 \mathrm{~min}$. Particulate debris was removed after centrifugation at $4000 \mathrm{rpm}$ and at $12,000 \mathrm{rpm}$ for $10 \mathrm{~min}$ each. The supernatant was stored at $-80^{\circ} \mathrm{C}$. Intestinal lamina propria $\lg \mathrm{A}$ was obtained by fine mincing $1 \mathrm{~cm}$ of ileum in PBS with protease Inhibitor (S8820-20TAB, Sigma, Life Science) followed by homogenization and storage at $-80^{\circ} \mathrm{C}$. For normalization, total protein concentration of the soluble fractions was measured by a Coomassie (Bradford) Protein Assay Kit (23200, Thermo Fisher Scientific). IgA levels were measured using a commercial ELISA Kit (88-50450-86, Thermo Fisher Scientific) as per manufacturer's instructions. Analyte concentrations were determined by comparison with standards, by using a standard curve generated as a 4-parameter curve fit to determine ELISA kit assay values.

\section{Flow cytometry}

Cells from indicated compartments were suspended in PBS with $1 \%$ fetal bovine serum, pre-incubated with anti-mouse CD16/32 (Fc-block, Clone 93, eBiosciences, San Diego, CA) and stained with anti-mouse fluorochromeconjugated antibodies (listed in Table S1). UltraComp eBeads ${ }^{\mathrm{TM}}$ Compensation Beads (01-2222-42, Invitrogen) were used for compensation. Acquisition of samples were performed using a Cytek Northern Light cytometer (Cytek, Fremont, CA). Flow-cytometry data were analyzed using the FLOWJO software (Tree Star, Ashland, OR).

\section{Analysis of fecal IgA bacterial coating}

Fecal pellets were collected in $1 \mathrm{~mL}$ of phosphate buffer saline (14190-144, Gibco), vortexed for $10 \mathrm{~min}$, homogenized, and centrifuged at $400 \times g$ to remove large debris. Supernatant was filtered through a sterile $70 \mu \mathrm{m}$ strainer and centrifuged at $8000 \times g$. The bacterial pellet was resuspended in PBS $0.25 \%$ BSA with SYTO BC (Thermofisher) and incubated for 30 min on ice. Then, bacteria were stained with PE anti-mouse IgA (clone: $\mathrm{mA}-6 \mathrm{E} 1$, $10 \mu \mathrm{g} / \mathrm{ml}$ ) for $20 \mathrm{~min}$ on ice, washed and resuspended in PBS $0.25 \%$ BSA with DAPI (Life Technologies) prior to flow cytometry using a low FSC and SSC threshold to allow bacterial detection.

\section{RNA extraction, cDNA synthesis, and real-time PCR}

Total RNA was isolated using RNeasy ${ }^{\circledR}$ Plus Mini kit (QIAGEN, Hilden, Germany) and CDNA was synthesized from $2000 \mathrm{ng}$ of total RNA using High Capacity cDNA Reverse Transcription Kit (Applied Biosystems, Foster City, CA) on a PTC-200 Thermal Cycler (Marshall Scientific, Hampton, NH). Pigr gene expression (Assay ID Mm00465049_m1, Thermo Fisher Scientific) was performed using TaqMan ${ }^{\circledR}$ Fast Universal PCR Master Mix (Applied Biosystems) and Gapdh gene expression (Assay ID Mm99999915_g1, Thermo Fisher Scientific) was amplified as endogenous controls using Step One Plus Instrument (4376600, Applied Biosystems). Relative Pigr gene expression was calculated from reference gene using $\mathrm{CT}$ values obtained from Applied BioSystems' StepOne Software (Version v2.3).

The mRNA expression levels of IgA was performed using SYBR ${ }^{\circledR} F A S T$ qPCR kit (cat. \#4385612, Applied Biosystems, CA) with thermal conditions of 20 -s preincubation at $95^{\circ} \mathrm{C}$ followed by 40 cycles at $95^{\circ} \mathrm{C}$ for $3 \mathrm{~s}$ and $60^{\circ}$ $\mathrm{C}$ for $30 \mathrm{~s}$. Gene expression was calculated using from reference gene using CT values obtained from Applied Biosystems' StepOne Software (Version v2.3) and using GAPDH as reference gene. The following primers were 


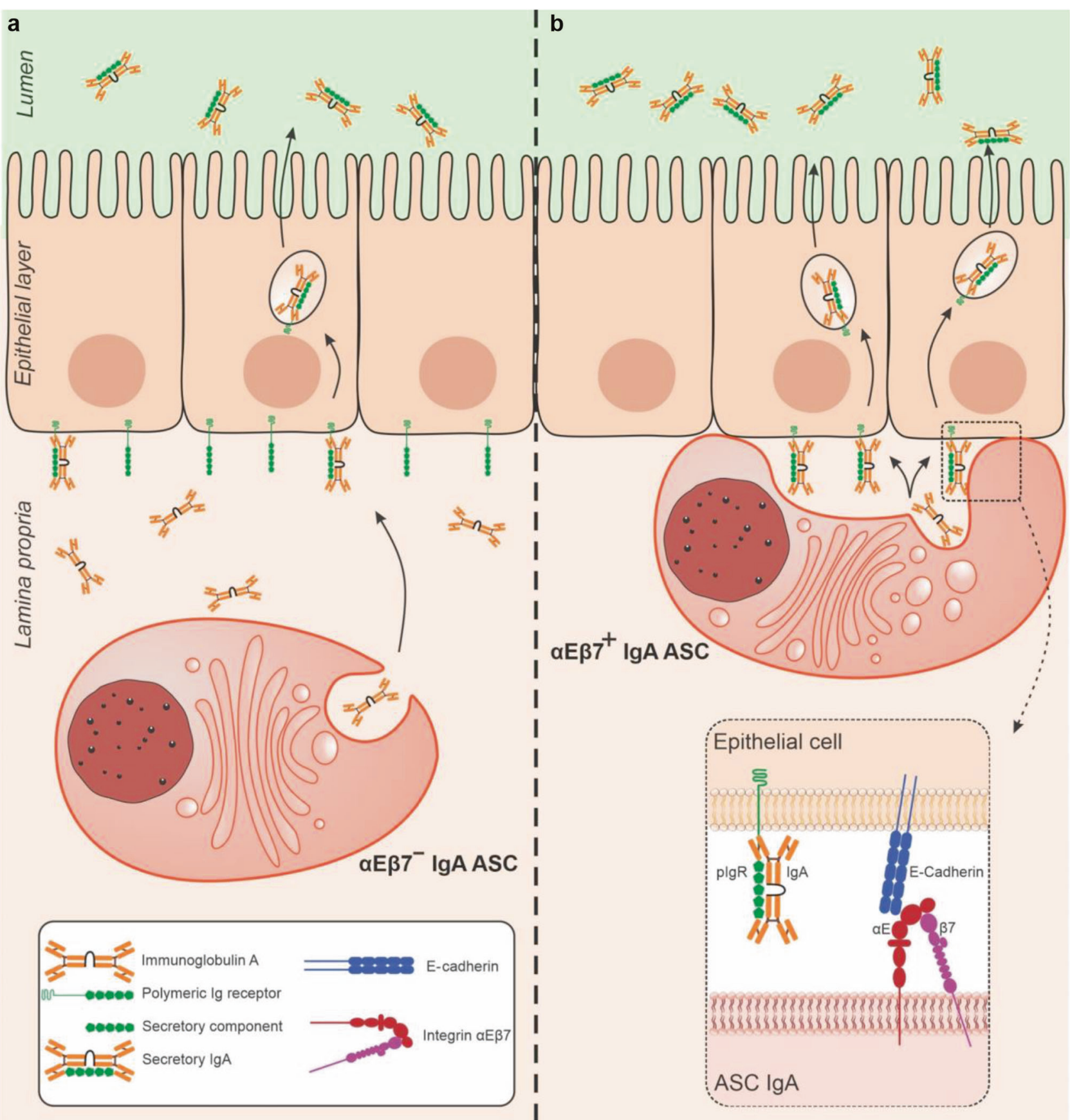

Fig. 6 Alternate integrin aE $\beta 7$-independent and dependent models of IgA transcytosis. a Canonical diffusion model for IgA transcytosis in which dlgA is secreted by $\lg A+$ ASC into the extracellular milieu and diffuses to reach plgR. $\mathbf{b}$ Proposed new model of $\alpha E \beta 7-d e p e n d e n t$ lgA transcytosis in which $\alpha E \beta 7+\lg A+A S C$ dock with IEC to directly relay dlgA to plgR for transcytosis into the intestinal lumen.

used to quantify transcripts in the tissue samples: immunoglobulin A ( $\lg A)$ F: 5'CCTAGTGTTGAGCCCCTAA3' and IgA R: 5'GGAAGTGCAGGGATACT TTG3'; (GAPDH) F: 5'GATTCCACCCATGGCAAATTC3' and GAPDH_R: 5TGGGATTTCCATTGATGACAAG3'.

\section{Immunostaining and confocal laser scanning microscopy acquisition}

Distal ileum $(10 \mathrm{~cm})$ samples were opened, fixed in $10 \%$ neutral buffered formalin, embedded in paraffin on edge, and cut into 4- $\mu$ m-thick sections. For immunofluorescence microscopy, sections were deparaffinized, rehydrated, and placed in a pressure cooker set to high pressure and heated for $20 \mathrm{~min}$ with Tris-EDTA pH 9.0 antigen retrieval buffer. The slides were stained using a 3D-printed Freequenza Rack (https://3dprint.nih.gov/ discover/3dpx-012172) and Shandon Plastic Coverplates (72110017, Thermo Fisher Scientific). After antigen retrieval slides were blocked in $5 \%$ normal donkey serum, $0.3 \%$ Triton $\mathrm{X}-100$ in PBS for $1 \mathrm{~h}$ at RT, and incubated with primary plgR antibody in PBS-T (0.1\% Tween 20$)$ for $18 \mathrm{~h}$ at $4^{\circ} \mathrm{C}$, washed in PBS-T, and stained with an anti-goat secondary for $1 \mathrm{~h}$ at RT. The slides were then washed and incubated for another $18 \mathrm{~h}$ at $4^{\circ} \mathrm{C}$ with either $\lg \mathrm{A}$ and $\mathrm{CD} 31$ or $\lg \mathrm{A}$ and E-cadherin, washed with PBS-T, and stained with secondaries for $1 \mathrm{~h}$ at RT. After another wash, they were counterstained with Hoechst (H3570, Thermo Fisher Scientific) 1:1000 in PBS. The slides were removed from the Freequenza rack and treated with TrueBlack Lipofuscin Autofluorescence Quencher (23007, Biotium, Fremont, CA) 1:20 in 70\% reagent alcohol, for $30 \mathrm{sec}$. The quencher was removed, and slides were washed in PBS. Specimens were mounted with ProLong Gold Antifade Mountant (P36930, ThermoFisher Scientific) and 
stored at RT. All antibodies details are listed in Table S2. Image acquisition was performed with a ZEISS LSM780 confocal microscope (Thornwood, USA) equipped with a 40x/1.3 NA EC Plan-Neofluor oil objective. Highresolution images were taken through a tile scan. Each square region was $610 \mu \mathrm{m}$ per side with a pixel size of $0.13 \mu \mathrm{m}$.

\section{TEM immunogold labeling}

For immunoelectron microscopic studies, distal ilea were fixed for $12 \mathrm{~h}$ in $4 \%$ PFA in $0.1 \mathrm{M}$ phosphate buffer, pelleted in $10 \%$ gelatin and cryoprotected by infusion with $2.3 \mathrm{M}$ sucrose overnight at $4{ }^{\circ} \mathrm{C}$. One $\mathrm{mm}^{3}$ tissue blocks were mounted onto specimen holders and snap frozen in liquid nitrogen. Ultrathin cryosections $(70-80 \mathrm{~nm})$ were cut, placed on a 1:1 mixture of $2.3 \mathrm{M}$ sucrose and $2 \%$ methyl cellulose $(15 \mathrm{cp})$ and transferred onto Formvar and carbon-coated copper grids.

Tissue grids were placed on $2 \%$ gelatin at $37^{\circ} \mathrm{C}$ for $20 \mathrm{~min}$, rinsed with $0.15 \mathrm{M}$ glycine/PBS and the sections were blocked using $1 \%$ cold water fish-skin gelatin. Ultrathin sections were incubated for $2 \mathrm{~h}$ at RT with purified rat anti-mouse IgA antibody (Clone C10-3. BD Pharmingen) diluted at 1:500 and rabbit anti-mouse E-Cadherin antibody (Clone 24E10, Cell Signaling), washed and followed by an $1 \mathrm{~h}$ incubation with $12 \mathrm{nM}$ gold conjugated goat anti-rat IgG (Jackson ImmunoResearch Inc.) and $16 \mathrm{~nm}$ gold conjugated goat anti-rabbit IgG (Jackson ImmunoResearch Inc., Westgrove, PA), diluted 1:20 in 1\% BSA/PBS. Sections were post-fixed for 5 min with $1 \%$ glutaraldehyde in PBS, washed thoroughly with distilled water, and then contrasted ( $10 \mathrm{~min}$ in $0.4 \%$ uranyl acetate and $1.8 \%$ methyl cellulose on ice). Grids were viewed using a JEOL 1400plus (JEOL, Peabody, MA) transmission electron microscope and photographed using a Oneview 4KGatan digital camera (Gatan, Pleasanton, CA).

\section{Quantification of plgR immunofluorescent signal}

Images were processed with ImageJ (Fiji) software. ${ }^{43}$ To quantify PlgR expression, values were obtained individually for the villus-crypt axis using a region of interest (ROI). First, free-hand ROI were created by delimiting the axis according to DAPI and E-cadherin label. This step was done by a masked observer (ZM) who was blinded to PlgR IF signal. Then, a macro was used to apply the ROI to the PlgR fluorescent image, the product of the area and mean intensity (Int Den) was recorded and expressed per each highresolution image. At least 5 villus-crypt axis per image were analyzed.

\section{IgA ASC morphology assessment}

The length of $\lg \mathrm{A}+\mathrm{ASC}$ was assessed following a semi-automatic method using ImageJ software. Briefly, a binary image was created applying a uniform IgA IF signal threshold to all images, which allowed generation of an ROI for each IgA cell. Then, a straight line was manually drawn along each ROI according to the maximum length of each cell, which automatically provides length in microns. Thirty or more cells were measured near the pericryptal base region for each mouse strain. The crypt base was identified by its small luminal space.

\section{Cell sorting}

Single-cells suspension of LPMC were depleted of $\mathrm{CD}^{+}$cells using CD3ع MicroBead Kit (130-094-973, Miltenyi Biotec) and LS columns (130-042-401, Miltenyi Biotec) and stained with anti-mouse CD19 PerCpCy5.5 (115534, Biolegend, San Diego, CA), anti-mouse CD3 APC-eFluor 780 (47-0032-82, Invitrogen), anti-mouse IgA PE (12-4204-83, Invitrogen), anti-mouse CD103 APC (17-1031-82, Invitrogen) and anti-mouse Integrin B7 BV421 (564283, $\mathrm{BD}$ Bioscience, La Jolla, CA) and sorted on a fluorescence-activated cell sorter FACSAria (BD Biosciences) using FACSDiva software (BD Biosciences).

\section{Transmission electron microscopy and nucleo-cytoplasmic ratio analysis}

Cells were fixed with $2 \%$ glut. in $0.10 \mathrm{M}$ cacodylate buffer and further postfixed in $1 \% \mathrm{OsO} 4$ in $0.1 \mathrm{M}$ cacodylate buffer for $1 \mathrm{~h}$ on ice. Cells were stained with $2 \%$ uranyl acetate for $1 \mathrm{~h}$ on ice, dehydrated in ethanol $(50-100 \%)$ on ice followed by 2 washes with acetone (10 min each) and embedded with Durcupan (44611, Sigma Aldrich). Sections were cut at 60 $\mathrm{nm}$ on a Leica UCT ultramicrotome (Wetzlar, Germany), and placed on 300 mesh copper grids. Sections were post-stained with $2 \%$ uranyl acetate for $5 \mathrm{~min}$ and Sato's lead stain for $1 \mathrm{~min}$. Images were obtained by using Jeol 1400 plus Transmission Electron Microscope equipped with Gatan digital camera (Peabody, MA). The nucleus/cytoplasm ratio analysis was performed with ImageJ software (Fiji). The calculation was then carried out by applying two regions of interest (ROIs), one delimiting the total area per cell and other delimiting the nuclear area corresponding to each one.

\section{Bulk RNA-sequencing and analysis}

Total cellular RNA was extracted from the 4 sorted populations: CD19 ${ }^{+}$ $\lg A^{-}, \mathrm{CD}_{19}{ }^{+} \operatorname{lgA} \mathrm{A}^{+}, \mathrm{CD}_{19}{ }^{-} \lg \mathrm{A}^{+} \mathrm{CD} 103^{-}$and $\mathrm{CD} 19^{-} \operatorname{lgA} \mathrm{C}^{+} \mathrm{CD} 103^{+}$in TRlzol reagent (15596018, Invitrogen). RNA library preparation was conducted using a TruSeq RNA Library Prep Kit v2 for Illumina (RS-122-2001, Illumina, San Diego, CA) according to the manufacturer's protocols. After quality assessment, sequencing was carried out on a NovaSeq 6000 (Illumina) using single-ended 50-bp reads. Quality control of the raw fastq files was performed using the software tool FastQC v0.11.3. Sequencing reads were trimmed with Trimmomatic $v 0.36$ and aligned with the mouse genome (GRCm38) using the STAR aligner v2.5.3a. Read quantification was performed with RSEM ${ }^{44}$ v1.3.0 and the M19 Gencode annotation. ${ }^{45}$ The $\mathrm{R}$ BioConductor packages edgeR and limma were used to implement the limma-voom method for differential expression analysis. In brief, lowly expressed genes - those not having counts per million (cpm) $\geq 3$ in at least 3 of the samples-were filtered out and then trimmed mean of M-values (TMM) normalization was applied. The experimental design was modeled upon condition and batch $(\sim 0+$ condition + batch). The voom method was employed to model the mean-variance relationship in the log-cpm values weighted for inter-subject correlations in repeated measures of mice, after which ImFit was used to fit per-gene linear models ${ }^{46}$. Empirical Bayes moderation was applied with the eBayes function. Significance was defined by using an adjusted $p$ value cut-off of 0.05 after multiple testing correction using a moderated t-statistic in limma. Functional enrichment of the differentially expressed genes was performed using WebGestalt ${ }^{47}$ (including GSEA $^{48}$ ), GSVA ${ }^{49}$ and SPIA. ${ }^{50}$

\section{Statistical analysis}

Results are expressed as mean \pm S.D. unless otherwise indicated. One- or two-way analysis of variance with Bonferroni or Dunnett's post-hoc tests were used to compare groups. Significance was set at $p<0.05$ and twotailed tests were used in all experiments. Calculations were performed using GraphPad Prism version 8 software (GraphPad Software, La Jolla, CA).

\section{REFERENCES}

1. Wagner, N. et al. Critical role for beta7 integrins in formation of the gutassociated lymphoid tissue. Nature 382, 366-370 (1996).

2. Schippers, A. et al. beta7 integrin controls immunogenic and tolerogenic mucosal B cell responses. Clin. Immunol. 144, 87-97 (2012).

3. Schippers, A. et al. Mucosal addressin cell-adhesion molecule-1 controls plasmacell migration and function in the small intestine of mice. Gastroenterology 137, 924-933 (2009).

4. Cerf-Bensussan, N. et al. A monoclonal antibody (HML-1) defining a novel membrane molecule present on human intestinal lymphocytes. Eur. J. Immunol. 17, 1279-1285 (1987).

5. Schwarting, R., Dienemann, D., Kruschwitz, M., Fritsche, G. \& Stein, H. Specificities of monoclonal antibodies B-ly7 and HML-1 are identical. Blood 75, 320-321 (1990).

6. Visser, L., Shaw, A., Slupsky, J., Vos, H. \& Poppema, S. Monoclonal antibodies reactive with hairy cell leukemia. Blood 74, 320-325 (1989).

7. Kilshaw, P. J. \& Murant, S. J. A new surface antigen on intraepithelial lymphocytes in the intestine. Eur. J. Immunol. 20, 2201-2207 (1990).

8. Roberts, K. \& Kilshaw, P. J. The mucosal T cell integrin alpha M290 beta 7 recognizes a ligand on mucosal epithelial cell lines. Eur. J. Immunol. 23, 1630-1635 (1993).

9. Karecla, P. I., Bowden, S. J., Green, S. J. \& Kilshaw, P. J. Recognition of E-cadherin on epithelial cells by the mucosal T cell integrin alpha M290 beta 7 (alpha E beta 7). Eur. J. Immunol. 25, 852-856 (1995).

10. Kilshaw, P. J. Expression of the mucosal T cell integrin alpha M290 beta 7 by a major subpopulation of dendritic cells in mice. Eur. J. Immunol. 23, 3365-3368 (1993).

11. Iwata, M. et al. Retinoic acid imprints gut-homing specificity on T cells. Immunity 21, 527-538 (2004).

12. Mora, J. R. et al. Generation of gut-homing IgA-secreting B cells by intestinal dendritic cells. Science 314, 1157-1160 (2006).

13. Benson, M. J., Pino-Lagos, K., Rosemblatt, M. \& Noelle, R. J. All-trans retinoic acid mediates enhanced T reg cell growth, differentiation, and gut homing in the face of high levels of co-stimulation. J. Exp. Med 204, 1765-1774 (2007).

14. Mora, J. R. \& von Andrian, U. H. Role of retinoic acid in the imprinting of guthoming IgA-secreting cells. Semin Immunol. 21, 28-35 (2009). 
15. Jaensson, E. et al. Small intestinal CD103+ dendritic cells display unique functional properties that are conserved between mice and humans. J. Exp. Med 205, 2139-2149 (2008).

16. Csencsits, K. L., Walters, N. \& Pascual, D. W. Cutting edge: dichotomy of homing receptor dependence by mucosal effector B cells: alpha(E) versus L-selectin. J. Immunol. 167, 2441-2445 (2001).

17. Pascual, D. W., Riccardi, C. \& Csencsits-Smith, K. Distal IgA immunity can be sustained by alphaEbeta7+ B cells in L-selectin-/- mice following oral immunization. Mucosal Immunol. 1, 68-77 (2008).

18. Schon, M. P. et al. Mucosal T lymphocyte numbers are selectively reduced in integrin alpha E (CD103)-deficient mice. J. Immunol. 162, 6641-6649 (1999).

19. Johansen, F. E. et al. Absence of epithelial immunoglobulin A transport, with increased mucosal leakiness, in polymeric immunoglobulin receptor/secretory component-deficient mice. J. Exp. Med. 190, 915-922 (1999).

20. Kaetzel, C. S., Robinson, J. K., Chintalacharuvu, K. R., Vaerman, J. P. \& Lamm, M. E. The polymeric immunoglobulin receptor (secretory component) mediates transport of immune complexes across epithelial cells: a local defense function for lgA. Proc. Natl Acad. Sci. USA 88, 8796-8800 (1991).

21. Mombaerts, $P$. et al. RAG-1-deficient mice have no mature $B$ and T lymphocytes. Cell 68, 869-877 (1992)

22. Kim, M. H., Taparowsky, E. J. \& Kim, C. H. Retinoic acid differentially regulates the migration of innate lymphoid cell subsets to the gut. Immunity 43, 107-119 (2015).

23. Oracki, S. A., Walker, J. A., Hibbs, M. L., Corcoran, L. M. \& Tarlinton, D. M. Plasma cell development and survival. Immunol. Rev. 237, 140-159 (2010).

24. Shaffer, A. L. et al. Blimp-1 orchestrates plasma cell differentiation by extinguishing the mature B cell gene expression program. Immunity 17, 51-62 (2002).

25. Kallies, A. et al. Plasma cell ontogeny defined by quantitative changes in blimp-1 expression. J. Exp. Med 200, 967-977 (2004).

26. Chevrier, S. et al. The BTB-ZF transcription factor Zbtb20 is driven by Irf4 to promote plasma cell differentiation and longevity. J. Exp. Med 211, 827-840 (2014).

27. Nutt, S. L., Taubenheim, N., Hasbold, J., Corcoran, L. M. \& Hodgkin, P. D. The genetic network controlling plasma cell differentiation. Semin Immunol. 23, 341-349 (2011)

28. Eberl, G. Inducible lymphoid tissues in the adult gut: recapitulation of a fetal developmental pathway? Nat. Rev. Immunol. 5, 413-420 (2005).

29. Mesin, L., Di Niro, R., Thompson, K. M., Lundin, K. E. \& Sollid, L. M. Long-lived plasma cells from human small intestine biopsies secrete immunoglobulins for many weeks in vitro. J. Immunol. 187, 2867-2874 (2011).

30. Cepek, K. L., Parker, C. M., Madara, J. L. \& Brenner, M. B. Integrin alpha E beta 7 mediates adhesion of $\mathrm{T}$ lymphocytes to epithelial cells. J. Immunol. 150, 3459-3470 (1993).

31. Dogan, A., Wang, Z. D. \& Spencer, J. E-cadherin expression in intestinal epithelium. J. Clin. Pathol. 48, 143-146 (1995).

32. Hoytema van Konijnenburg, D. P. et al. Intestinal epithelial and intraepithelial T cell crosstalk mediates a dynamic response to infection. Cell 171, 783-794 e713 (2017).

33. Moller, P., Mielke, B. \& Moldenhauer, G. Monoclonal antibody HML-1, a marker for intraepithelial $\mathrm{T}$ cells and lymphomas derived thereof, also recognizes hairy cell leukemia and some B-cell lymphomas. Am. J. Pathol. 136, 509-512 (1990).

34. Ghosh, S. et al. Natalizumab for active Crohn's disease. N. Engl. J. Med 348, 24-32 (2003).

35. Sandborn, W. J. et al. Vedolizumab as induction and maintenance therapy for Crohn's disease. N. Engl. J. Med 369, 711-721 (2013).

36. Feagan, B. G. et al. Vedolizumab as induction and maintenance therapy for ulcerative colitis. N. Engl. J. Med 369, 699-710 (2013).

37. Perez-Jeldres, T. et al. Cell trafficking interference in inflammatory bowel disease: therapeutic interventions based on basic pathogenesis concepts. Inflamm. Bowel Dis. 25, 270-282 (2019).

38. Babbar, A. et al. The compromised mucosal immune system of beta7 integrindeficient mice has only minor effects on the fecal microbiota in homeostasis. Front Microbiol 10, 2284 (2019).

39. Shi, W. et al. Transcriptional profiling of mouse B cell terminal differentiation defines a signature for antibody-secreting plasma cells. Nat. Immunol. 16, 663-673 (2015)

40. Brandtzaeg, P. Transport models for secretory IgA and secretory IgM. Clin. Exp. Immunol. 44, 221-232 (1981).

41. Karuppuchamy, T. et al. Sphingosine-1-phosphate lyase inhibition alters the S1P gradient and ameliorates Crohn's-like ileitis by suppressing thymocyte maturation. Inflamm. Bowel Dis. 26, 216-228 (2020).

42. Bamias, G. et al. Proinflammatory effects of $\mathrm{TH} 2$ cytokines in a murine model of chronic small intestinal inflammation. Gastroenterology 128, 654-666 (2005).

43. Schindelin, J. et al. Fiji: an open-source platform for biological-image analysis. Nat. Methods 9, 676-682 (2012)
44. Li, B. \& Dewey, C. N. RSEM: accurate transcript quantification from RNA-Seq data with or without a reference genome. BMC Bioinforma. 12, 323 (2011).

45. Frankish, A. et al. GENCODE reference annotation for the human and mouse genomes. Nucleic Acids Res 47, D766-D773 (2019).

46. Law, C. W., Chen, Y., Shi, W. \& Smyth, G. K. voom: precision weights unlock linear model analysis tools for RNA-seq read counts. Genome Biol. 15, R29 (2014).

47. Zhang, B., Kirov, S. \& Snoddy, J. WebGestalt: an integrated system for exploring gene sets in various biological contexts. Nucleic Acids Res. 33, W741-W748 (2005).

48. Subramanian, A. et al. Gene set enrichment analysis: a knowledge-based approach for interpreting genome-wide expression profiles. Proc. Natl. Acad. Sci. USA 102, 15545-15550 (2005).

49. Hanzelmann, S., Castelo, R. \& Guinney, J. GSVA: gene set variation analysis for microarray and RNA-seq data. BMC Bioinforma. 14, 7 (2013).

50. Tarca, A. L. et al. A novel signaling pathway impact analysis. Bioinformatics 25 75-82 (2009).

\section{ACKNOWLEDGEMENTS}

We thank Joshua D. Boyer and Ying Jones (Electron Microscopy Facility, UCSD—School of Medicine) for technical assistance. The Flow Cytometry Core Facility (La Jolla Institute for Immunology), UC San Diego IGM Genomics Center and UC San Diego Center for Computational Biology \& Bioinformatics are gratefully acknowledged.

\section{AUTHOR CONTRIBUTIONS}

J.R.-N. supervised the overall project. M.G. and J.R.-N. designed the experiments and wrote the manuscript. M.G., L.L., S.Y., K.D., N.R.Z. and V.T. performed most of the experiments. C.J.T., Z.M., G.B. and J.R.-N. assisted with analysis of the data. All authors contributed to the interpretation of the data as well as proofreading the manuscript.

\section{FUNDING}

This work was supported by grants from the National Institutes of Health [DK108670, DK118927]; VA Merit BLRD-I01 BX003436; Takeda Pharmaceuticals U.S.A. IISR-2017102050 grant to JRN; San Diego Digestive Diseases Research Center [P30 DK120515] and support from Chiba University-UC San Diego Program in Mucosal Immunology, Allergy and Vaccines.

\section{COMPETING INTERESTS}

The authors declare no competing interests.

\section{ADDITIONAL INFORMATION}

Supplementary information The online version contains supplementary material available at https://doi.org/10.1038/s41385-021-00439-x.

Correspondence and requests for materials should be addressed to J.R-N.

Reprints and permission information is available at http://www.nature.com/ reprints

Publisher's note Springer Nature remains neutral with regard to jurisdictional claims in published maps and institutional affiliations.

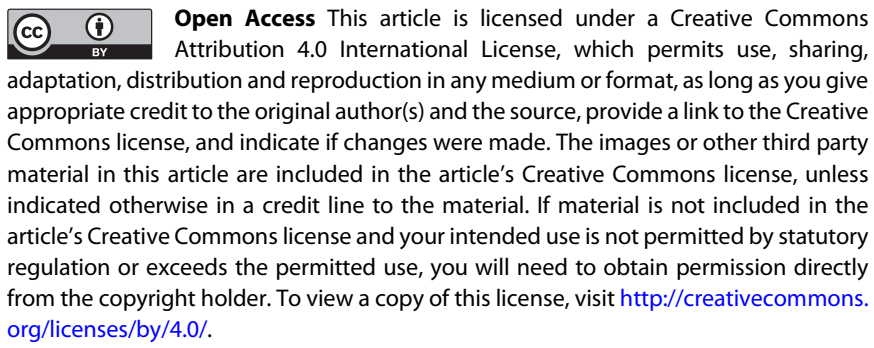

This is a U.S. government work and not under copyright protection in the U.S.; foreign copyright protection may apply 2021 